\title{
Resistência a benzimidazóis por Guignardia citricarpa
}

\author{
Maria Beatriz Calderan Rodrigues ${ }^{(1)}$, Fernando Dini Andreote ${ }^{(1)}$, Marcel Bellato Spósito(2), \\ Carlos Ivan Aguillar-Vildoso ${ }^{(1)}$, Welington Luiz Araújo(1) e Aline Aparecida Pizzirani-Kleiner ${ }^{(1)}$
}

\begin{abstract}
(1)Escola Superior de Agricultura Luiz de Queiroz, Dep. de Genética, Av. Pádua Dias, 11, Caixa Postal 83, CEP 13400-970 Piracicaba, SP. E-mail: mbcrodri@esalq.usp.br, fdandreo@esalq.usp.br, aguilarvildoso@terra.com.br, wlaraujo@esalq.usp.br, aapklein@esalq.usp.br (2)Fundecitrus, Dep. Científico, Av. Dr. Adhemar Pereira de Barros, 201, Caixa Postal 391, CEP 14807-040 Araraquara, SP.

E-mail: marcel@fundecitrus.com.br
\end{abstract}

\begin{abstract}
Resumo - O objetivo deste trabalho foi avaliar a resistência de Guignardia citricarpa aos fungicidas carbendazim e piraclostrobina, por meio de avaliação do crescimento em meio de cultura, decomposição de tecido foliar e produção de corpos de frutificação. Para isso, o fungo G. citricarpa foi isolado de lesões de frutos de laranja (Citrus sinensis), produzidos em área com intensa aplicação de fungicida. Os isolados obtidos foram avaliados quanto à sensibilidade aos fungicidas piraclostrobina e carbendazim, nas dosagens de $0,5,1 \mathrm{e} 2 \mu \mathrm{g} \mathrm{mL}{ }^{-1}$ de i.a., para se verificar o efeito da pressão de seleção causada pelo uso destes compostos em áreas citrícolas. Embora tenha sido observada redução efetiva no número de estruturas reprodutivas e na decomposição de folhas e frutos infectados com G. citricarpa, após a aplicação dos fungicidas, 7,5\% dos isolados avaliados sobre meio de cultura apresentaram resistência a esse fungicida, o que indica que pode ocorrer seleção de isolados resistentes no campo. Para a piraclostrobina não foi observada resistência, o que indica que pode ser um composto alternativo para ser utilizado de forma alternada com carbendazim, para diminuir as chances de ocorrência de resistência do patógeno.
\end{abstract}

Termos para indexação: mancha-preta dos citros, pinta-preta, tolerância a fungicidas, citricultura.

\section{Guignardia citricarpa resistance to benzimidazoles}

\begin{abstract}
The objective of this work was to evaluate the resistance of Guignardia citricarpa to pyraclostrobine and carbendazim fungicides, through: growth analysis in culture media amended with the fungicides; leaf decomposition; and production of reproductive structures on leaves naturally infected with these fungi. G. citricarpa was isolated from symptomatic fruits of sweet orange (Citrus sinensis) cultivated in area with intense fungicide application. The sensibility to fungicides of $G$. citricarpa isolates was evaluated with pyraclostrobine and carbendazim, in the doses $0.5,1 \mathrm{e} 2 \mu \mathrm{g} \mathrm{mL} \mathrm{L}^{-1}$ a.i., to verify the effect of selection pressure caused by continuous use of these compounds. Although, reduction on leaf decomposition and on the number of reproductive structures were observed after application of pyraclostrobine and carbendazim, $7.5 \%$ of the isolates, evaluated in culture media, exhibited resistance to carbendazim, suggesting that the use of this agrochemical must be combined to other active principles in a consortium to reduce the chances of resistance occurrence. No resistance to pyraclostrobine was observed among tested isolates, what indicates that this could be an alternative compound to be used in combination to carbendazim, to minimize the chance of resistance occurrence.
\end{abstract}

Index terms: citrus black-spot, fungicide resistance, citriculture.

\section{Introdução}

A mancha-preta dos citros (MPC), cujo agente causal é o fungo Guignardia citricarpa Kiely (anamorfo Phyllosticta citricarpa McAlpine 1973), é caracterizada por lesões na casca de frutos de laranjas doces, limões, tangerinas e seus híbridos, o que os torna depreciados para o mercado de fruta fresca. Quando o ataque é severo, é possível observar lesões também em ramos e folhas. Os diferentes tipos de lesões causadas pela doença ficam restritos ao flavedo e não afetam a qualidade interna dos frutos. A MPC pode também causar a queda prematura dos frutos, o que reduz significativamente a produção (Klotz, 1978; Spósito, 2003). 
Atualmente a doença está presente nos estados do Rio de Janeiro, São Paulo, Rio Grande do Sul, Minas Gerais, Espírito Santo, Santa Catarina, Amazonas e Paraná (Feichtenberger et al., 2005).

Entre as estratégias de controle da MPC, o controle químico é a mais utilizada, e são necessárias quatro pulverizações, em média, a partir da queda das pétalas. Os fungicidas registrados e de comprovada eficiência no controle da MPC restringem-se a: produtos protetores à base de cobre ou ditiocarbamatos; produtos sistêmicos, principalmente os benzimidazóis; e os translaminares como as estrobilurinas (Feichtenberger et al., 2005).

Os fungicidas protetores apresentam amplo espectro de ação. Por interferirem em diversos processos metabólicos vitais do fungo, esses produtos apresentam baixo risco de resistência pelo patógeno. Os fungicidas de ação sistêmica apresentam maior especificidade. Os benzimidazóis, por exemplo, afetam especificamente a divisão celular, pois apresentam atividade seletiva para a tubulina de fungos, e ligam-se a essa proteína, impedindo que ocorra a polimerização dos microtúbulos formadores do fuso mitótico (Kendall et al., 1994; Wheeler et al., 1995). Esta especificidade dos benzimidazóis faz com que esse fungicida apresente alto risco de resistência adquirida pelo patógeno. Devido a essas características, os isolados resistentes aos benzimidazóis geralmente são tão adaptados quanto os sensíveis. Portanto, a alta pressão de seleção causada pelo uso intensivo dos benzimidazóis pode resultar na seleção de isolados resistentes em um curto período de tempo.

Os fungicidas de ação translaminar, como as estrobilurinas, também possuem ação específica sobre o patógeno e apresentam alto risco de resistência. As estrobilurinas interferem na respiração mitocondrial, ao bloquear a transferência de elétrons pelo complexo citocromo bc1 (Ghini \& Kimati, 2000).

De modo geral, fungicidas pertencentes a um mesmo grupo químico apresentam resistência cruzada (Ghini \& Kimati, 2000). Entre os benzimidazóis, o carbendazim e o tiofanato metílico são os produtos utilizados para citros e passíveis de resistência cruzada. Para as estrobilurinas, a resistência cruzada pode ocorrer para a azoxistrobina, trifloxistrobina e piraclostrobina. Essa informação é importante na adoção de estratégias anti-resistência.

Devido ao baixo número de fungicidas eficazes no controle da MPC, geralmente usados também no manejo de outras doenças fúngicas na citricultura, tais como a podridão-floral (Colletotrichum acutatum Simmonds), verrugose (Elsinoe spp.), melanose (Diaporthe citri Wolf), torna-se necessária a adoção de estratégias anti-resistência, que contemplem um programa de controle efetivo.

Este trabalho teve como objetivos avaliar a resistência de isolados de G. citricarpa aos fungicidas carbendazim e piraclostrobina, por meio da avaliação do crescimento em meio de cultura, produção de corpos de frutificação e decomposição de tecidos foliares de citros.

\section{Material e Métodos}

Os isolados de G. citricarpa utilizados neste estudo foram obtidos de frutos sintomáticos de laranjas (Citrus sinensis L. Osbeck) das variedades Pêra, Valência e Natal, coletados em diferentes regiões produtoras de citros do Estado de São Paulo, onde a doença apresenta-se endêmica e tem sido controlada com intensa aplicação de fungicidas.

O fungo G. citricarpa foi isolado de 255 lesões típicas da MPC, a partir de 51 frutos de C. sinensis. Para isso, as amostras foram desinfestadas superficialmente, por meio de lavagem por: $30 \mathrm{~s}$ em etanol 70\%; 1 min em hipoclorito de sódio 2\%; 1 min em água destilada esterilizada. Após a desinfestação superficial, G. citricarpa foi isolada em meio batata-dextrose-ágar (BDA), suplementado com tetraciclina $2 \%\left(50 \mu \mathrm{g} \mathrm{mL}^{-1}\right)$ e penicilina $2 \%\left(50 \mu \mathrm{g} \mathrm{mL} \mathrm{m}^{-1}\right)$. As placas foram incubadas a $28^{\circ} \mathrm{C}$ e avaliadas depois de três dias. Extremidades das hifas de colônias morfologicamente semelhantes ao gênero Guignardia foram coletadas e repicadas em meio BDA, purificadas e utilizadas no teste de resistência aos fungicidas utilizados em campo. A frequiência de isolamento foi determinada pela porcentagem de fragmentos que exibiam crescimento de G. citricarpa.

Os isolados de G. citricarpa obtidos, juntamente com um isolado endofítico (G. mangiferae Roy) e dois patogênicos, foram avaliados quanto à sensibilidade, em diferentes concentrações $\left(0,0,5,1\right.$ e $\left.2 \mu \mathrm{g} \mathrm{mL}^{-1}\right)$, aos fungicidas: carbendazim (produto comercial: Derosal 500), de acordo com método padrão (Brent, 1995); e piraclostrobina (produto comercial: Comet 250), que por não apresentar método padrão foi avaliado de acordo com método estabelecido para benzimidazóis. 
As colônias foram incubadas por 15 dias, a $28^{\circ} \mathrm{C}$. Após esse período, os isolados que apresentaram crescimento foram considerados resistentes aos fungicidas. A resistência também foi determinada pela medida do diâmetro de crescimento das colônias em relação à testemunha, que continha somente meio BDA. Foram realizadas quatro repetições por tratamento e as médias foram comparadas pelo teste de Tukey, a $5 \%$ de probabilidade.

A resistência de G. citricarpa a esses fungicidas foi, também, avaliada por meio da produção de corpos de frutificação e decomposição de folhas de citros. Para isso, foi utilizado método modificado de Schinor et al. (2002), pelo qual as folhas de laranja 'Valência', com aspecto de maduras e com coloração verde oliva, foram destacadas, inteiramente ao acaso, à altura de aproximadamente $1 \mathrm{~m}$. O pomar já apresentava, visualmente, fonte natural de inóculo de G. citricarpa, com frutos com sintomas e folhas em decomposição com produção de pseudotécios de Guignardia. Além disso, nessa área, não foi realizado nenhum tipo de controle de doenças.

As folhas coletadas foram lavadas em água corrente e secadas em papel. Em seguida, foram mergulhadas por 1 min em soluções dos fungicidas carbendazim e piraclostrobina, na concentração de $1 \mathrm{~mL} \mathrm{~L}^{-1}$ do produto comercial, secadas ao ar livre por 2 horas, colocadas em sacos de plástico transparentes e incubadas a $25^{\circ} \mathrm{C}$, com fotoperíodo de 12 horas. Semanalmente, as folhas foram secadas para evitar a alta umidade. Cada tratamento foi realizado com quatro repetições, com dez folhas cada. $O$ tratamento controle consistiu de folhas somente imersas em água. O número de folhas com estruturas de G. citricarpa (fase sexuada) ou Phyllosticta citricarpa (fase assexuada), bem como seu estado de decomposição, foram avaliados após 14 e 28 dias. Para a avaliação, a área colonizada foi estimada pelo uso de uma escala de notas de 0 a 7 , que foram: 0 , folhas sem estruturas; 1 , folhas com até 5\% da área com estruturas; 2 , folhas com 5 a $10 \%$ da área com estruturas; 3 , folhas com 10 a $20 \%$ da área com estruturas; 4 , folhas com 20 a $40 \%$ da área com estruturas; 5 , folhas com 40 a $60 \%$ da área com estruturas; 6, folhas com 60 a $80 \%$ da área com estruturas; 7, folhas com mais de $80 \%$ da área com estruturas (Bizari et al., 2003).

Para a avaliação do estado de decomposição das folhas, outra escala de notas, de 0 a 9, foi utilizada: 0 , folhas verdes, intactas, como no estado inicial do experimento; 1 , folhas com início da degradação da clorofila, intactas; 2 , folhas semi-papiráceas, intactas, de coloração amarelada; 3 , folhas papiráceas, intactas, de coloração amarelo palha; 4, folhas sem rendilhamento, mas no início da decomposição; 5, folhas sem rendilhamento, com média decomposição; 6 , folhas sem rendilhamento, totalmente decompostas; 7 , folhas com até $25 \%$ da área rendilhada; 8, folhas com 25 a $50 \%$ da área rendilhada; 9, folhas com mais de 50\% da área rendilhada (Bizari et al., 2003).

A análise estatística dos experimentos de colonização e decomposição de folhas destacadas foi feita sem transformação dos dados, e as médias de quatro repetições, com dez folhas cada, foram comparadas por meio do teste de Tukey.

\section{Resultados e Discussão}

Foram obtidos 21 isolados com características de G. citricarpa, que apresentaram uma freqüência de isolamento de 0,08. Este resultado difere dos de Araújo et al. (2001) e Glienke-Blanco et al. (2002), que obtiveram índices de isolamento em torno de 0,20 , ao utilizar amostras de folhas para o isolamento desta espécie. Isto sugere que a eficiência de isolamento de Guignardia spp. pode ser dependente da parte da planta utilizada. Os isolados obtidos estão mantidos na coleção do Laboratório de Genética de Microrganismos, do Departamento de Genética da Esalq. Foram obtidos 12 isolados de laranja 'Valência', sete da variedade Natal e dois da laranja 'Pêra'.

Todos os 24 isolados de G. citricarpa analisados foram sensíveis ao fungicida piraclostrobina e, embora nenhum protocolo de avaliação in vitro da resistência a esse fungicida tenha sido previamente estabelecido, a estratégia utilizada mostrou-se eficiente. Dois isolados $(7,5 \%)$ foram capazes de se desenvolver em meio de cultura suplementado com o fungicida carbendazim (Tabela 1), o que mostra que embora o crescimento te-

Tabela 1. Sensibilidade (diâmetro das colônias em $\mathrm{cm}$ ) de isolados de Guignardia citricarpa aos fungicidas carbendazim e piraclostrobina ${ }^{(1)}$.

\begin{tabular}{cccc}
\hline $\begin{array}{c}\text { Concentração } \\
\left(\mu \mathrm{g} \mathrm{mL}^{-1}\right)\end{array}$ & $\begin{array}{c}\text { Isolados } \\
\text { sensíveis }\end{array}$ & $\begin{array}{c}\text { Isolado } \\
\mathrm{L} 4\end{array}$ & $\begin{array}{c}\text { Isolado } \\
\mathrm{S} 7\end{array}$ \\
\hline Carbendazim $\left(\mu \mathrm{g} \mathrm{mL}^{-1}\right)$ & & & \\
0,0 & $7,5 \pm 1,0$ & $4,0 \pm 2,0 \mathrm{~A}$ & $8,0 \pm 1,0 \mathrm{~A}$ \\
0,5 & 0 & $2,5 \pm 0,5 \mathrm{AB}$ & $5,7 \pm 1,2 \mathrm{~A}$ \\
1,0 & 0 & $2,0 \pm 0,0 \mathrm{AB}$ & $2,8 \pm 1,3 \mathrm{~B}$ \\
2,0 & 0 & $1,2 \pm 0,3 \mathrm{~B}$ & $1,7 \pm 0,3 \mathrm{~B}$ \\
\hline Piraclostrobina $\left(\mu \mathrm{g} \mathrm{mL}^{-1}\right)$ & & & \\
0,0 & $7,5 \pm 0,8$ & $3,0 \pm 0,4$ & $8,0 \pm 1,1$ \\
0,5 & 0 & 0 & 0 \\
1,0 & 0 & 0 & 0 \\
2,0 & 0 & 0 & 0 \\
\hline
\end{tabular}

(1)Valores seguidos por letras iguais, na coluna, não diferem entre si pelo teste de Tukey, a 5\% de probabilidade. 
nha sido menor que aquele observado para o controle (meio de cultura sem fungicida), estes isolados foram resistentes a diferentes dosagens de carbendazim.

$\mathrm{O}$ uso de fungicidas continua sendo essencial para um controle efetivo da MPC. No entanto, a resistência aos benzimidazóis na África do Sul tem aumentado e é a principal preocupação dos produtores de citros daquele país. Schutte et al. (2003) mostraram que uma opção para conter ou eliminar o desenvolvimento de resistência a benzimidazóis seria o uso de estrobilurinas, que têm demonstrado eficiência no controle da MPC na África do Sul.

A resistência de um fungo a um fungicida com modo de ação específico pode ser facilmente avaliada em meio de cultura agarizado, que contenha uma concentração subletal do produto tóxico ao tipo selvagem do fungo. Mas, o aparecimento da chamada resistência de laboratório não implica, necessariamente, que problemas de resistência irão aparecer em condições de campo (Brent, 1995). A observação de resistência em laboratório somente indica uma primeira evidência experimental de sua existência, porém, para a obtenção de resistência prática, além da observação de isolados resistentes em laboratório, experimentos de campo devem ser feitos para diagnosticar falhas no controle.

A avaliação da produção de corpos de frutificação do fungo G. citricarpa, em folhas de citros, permitiu tanto a avaliação da colonização quanto da decomposição das folhas pelo inóculo natural do patógeno. A utilização de escalas diagramáticas para a avaliação do desenvolvimento de G. citricarpa já havia sido demonstrada por Spósito et al. (2003), que utilizaram uma escala diagramática baseada na ocorrência de sintomas da MPC, para estudar a severidade e a evolução da doença em pomares afetados.

As notas referentes à escala diagramática mostraram uma melhor diferenciação entre os tratamentos, na avaliação realizada 28 dias após a incubação do experimento. Embora tenha sido detectada a presença de isolados resistentes ao fungicida carbendazim, deve ser levado em consideração que esses isolados foram obtidos de uma área com intensa aplicação deste fungicida, fato que pode ter selecionado genótipos resistentes. No entanto, a aplicação do carbendazim em folhas infectadas de área sem histórico de aplicação desse fungicida mostrou, aos 14 dias, um controle efetivo de G. citricarpa, porém, aos 28 dias, a piraclostrobina foi mais eficiente (Tabela 2).

Em relação à decomposição, observou-se que aos 14 dias a piraclostrobina permitiu uma menor degradação das folhas, mas aos 28 dias, folhas tratadas com carbendazim apresentaram menor decomposição (Tabela 3).
Tabela 2. Efeito de fungicidas (escala de notas de 0 a 7) na colonização e produção de corpos de frutificação de Guignardia citricarpa, em folhas destacadas de laranja 'Valência' naturalmente infectadas ${ }^{(1)}$.

\begin{tabular}{lll}
\hline Tratamento & 14 dias & 28 dias \\
\hline Água & $0,83 \mathrm{a}$ & $1,97 \mathrm{a}$ \\
Piraclostrobina & $0,50 \mathrm{ab}$ & $0,02 \mathrm{c}$ \\
Carbendazim & $0,30 \mathrm{~b}$ & $0,40 \mathrm{~b}$ \\
\hline
\end{tabular}

(1) Valores seguidos por letras iguais, nas colunas, não diferem entre si pelo teste de Tukey, a $5 \%$ de probabilidade.

Tabela 3. Efeito de fungicidas (escala de notas de 0 a 9) na decomposição de folhas destacadas de laranja 'Valência' naturalmente infectadas por Guignardia citricarpa ${ }^{(1)}$.

\begin{tabular}{lll}
\hline Tratamento & 14 dias & 28 dias \\
\hline Água & $3,00 \mathrm{a}$ & $3,00 \mathrm{a}$ \\
Carbendazim & $2,65 \mathrm{ab}$ & $2,92 \mathrm{a}$ \\
Piraclostrobina & $2,33 \mathrm{~b}$ & $3,00 \mathrm{a}$ \\
\hline
\end{tabular}

(1)Valores seguidos por letras iguais, nas colunas, não diferem entre si pelo teste de Tukey, a 5\% de probabilidade.

Neste experimento, foi possível observar a formação de estruturas de G. citricarpa em restos culturais em decomposição no solo.

A constatação de isolados resistentes ao carbendazim, obtidos em campo, é um indício de que está surgindo resistência a esse fungicida nos pomares citrícolas brasileiros.

\section{Conclusões}

1. Existe resistência em isolados de Guignardia citricarpa, obtidos em áreas com elevada freqüência de aplicação de fungicidas benzimidazóis.

2. A aplicação de carbendazim e piraclostrobina, em folhas infectadas de áreas sem histórico de aplicação destes fungicidas, controla de forma eficiente a produção de ascósporos e decomposição da folha por G. citricarpa.

\section{Agradecimentos}

Ao Fundo Paulista de Defesa da Citricultura (Fundecitrus), pelo suporte financeiro; ao Conselho Nacional de Desenvolvimento Científico e Tecnológico (CNPq), pela concessão de bolsa.

\section{Referências}

ARAÚJO, W.L.; MACCHERONI JUNIOR, W.; AGUILARVILDOSO, C.I.; BARROSO, P.A.V.; SARIDAKIS, H.O.; AZEVEDO, J.L. Variability and interactions between endophytic bacteria and fungi isolated from leaf tissues of citrus rootstocks. Canadian Journal of Microbiology, v.47, p.229-236, 2001. 
BIZARI, D.R.; SCHINOR, E.H.; AGUILAR-VILDOSO, C.I. Reprodução de Guignardia citricarpa em folhas cítricas sob diferentes acondicionamentos. Summa Phytopathologica, v.29, p.83, 2003.

BRENT, K.J. Fungicide resistance in crop pathogens: how can it be managed? Brussels: GCPF, 1995. 49p. (FRAC. Monograph, 1).

FEICHTENBERGER, E.; BALDASSARI, R.B.; SPÓSITO, M.B.; BELASQUE JUNIOR, J. Doenças dos citros. In: KIMATI, H.; AMORIM, L.; REZENDE, J.A.M.; BERGAMIN FILHO, A.; CAMARGO, L.E.A. (Ed.). Manual de fitopatologia. São Paulo: Ceres, 2005. v.2, p.239-269.

GHINI, R.; KIMATI, H. Resistência de fungos a fungicidas. Jaguariúna: Embrapa Meio Ambiente, 2000. 78p.

GLIENKE-BLANCO, C.; AGUILAR-VILDOSO, C.I.; VIEIRA, M.L.C.; BARROSO, P.A.V.; AZEVEDO, J.L. Genetic variability in the endophytic fungus Guignardia citricarpa isolated from citrus plants. Genetics and Molecular Biology, v.25, p.251-255, 2002.

KENDALL, S.; HOLLOMON, D.W.; ISHII, H.; HEANEY, S.P. Characterization of benzimidazole-resistant strains of Rhynchosporium secalis. Pesticide Science, v.40, p.175-181, 1994.
KLOTZ, L.J. Fungal, bacterial, and nonparasitic diseases and injuries originating in the seedbed, nursery, and orchard. In: REUTHER, W.; CALAVAN, E.C.; CARMAN, G.E. (Ed.). The citrus industry. Riverside: University of California, 1978. v.4, p.1-66.

SCHINOR, E.H.; MOURÃO FILHO, F.A.A.; AGUILARVILDOSO, C.I.; TEÓFILO SOBRINHO, J. Colonização de folhas de laranjeira 'Pêra' e variedades afins por Guignardia citricarpa. Fitopatologia Brasileira, v.27, p.479-483, 2002.

SCHUTTE, G.C.; MANSFIELD, R.I.; SMITH, H.; BEETON, K.V. Application of Azoxystrobin for control of benomyl-resistant Guignardia citricarpa on 'Valencia' oranges in South Africa. Plant Disease, v.87, p.784-788, 2003.

SPÓSITO, M.B. Dinâmica temporal e espacial da mancha-preta (Guignardia citricarpa) e quantificação dos danos causados à cultura dos citros. 2003. 112p. Tese (Doutorado) - Escola Superior de Agricultura Luiz de Queiroz, Piracicaba.

WHEELER, I.E.; KENDALL, S.J.; BUTTERS, J.; HOLLOMON, D.W.; HALL, L. Using allele-specific oligonucleotide probes to characterize benzimidazole resistance in Rhynchosporium secalis. Pesticide Science, v.43, p.201-209, 1995.

$\overline{\text { Recebido em } 2 \text { de março de } 2006 \text { e aprovado em } 13 \text { de novembro de } 2006}$ 